\title{
Mevlüt Akçapa, Rus Dış Politikasında Etkili Bir Aktör: Gazprom, Putin Dönemi Rusya-Sırbistan Illişkilerinde Enerji Faktörü, Bursa: Dora Basım Yayın, 2020, 260 s. ISBN: 978-605-2471-81-4
}

Berat $\operatorname{Ali}^{1}($ C)

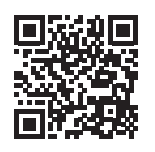

'Sorumlu yazar/Corresponding author: Berat Ali, (Yüksek Lisans Öğrencisi),

İstanbul Üniversitesi, Sosyal Bilimler Enstitüsü, Avrasya Araştırmaları Anabilim Dalı, İstanbul, Türkive

E-posta: berat.alii@gmail.com ORCID: 0000-0001-8944-3518

Başvuru/Submitted: 19.01.2021

Kabul/Accepted: 22.01 .2021

Atıf/Citation: Ali, Berat. "Rus Dıș Politikasında Etkili Bir Aktör: Gazprom, Putin Dönemi RusyaSırbistan Illişkilerinde Enerji Faktörü, adlı eserin tanıtımı. Avrasya incelemeleri Dergisi - Journal of Eurasian Inquiries 10, 1 (2021): 193-196. https://doi.org/10.26650/jes.2021.009
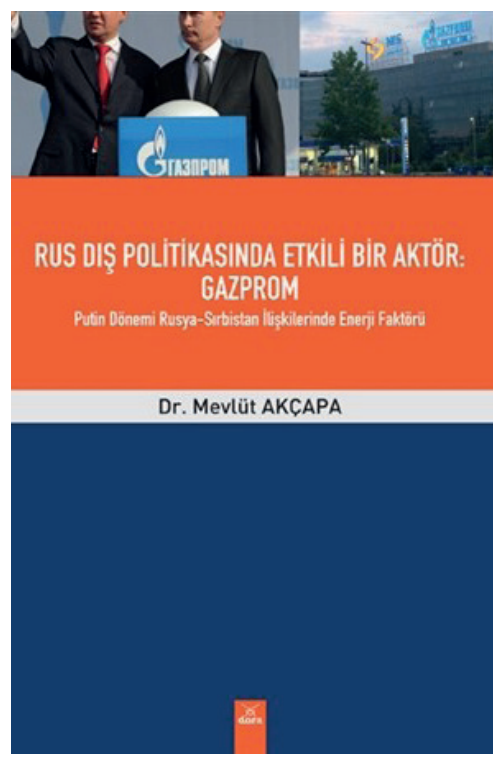

Çarlık Rusya'sı ve Sovyetler Birliği dönemlerinin ardından kurulan Rusya Federasyonu'nun dış politikasında yeni eğilimler gözlenmektedir. 2000 yılı itibariyle iktidara gelen Vladimir Putin, güce dayalı militarist dış politika yerine enerji merkezli bir dış politika izlemiştir. Çarlık ve Sovyet döneminde ideolojik etkenlerle oluşturulan Rus dış politikası, Putin dönemiyle birlikte daha pragmatik bir altyapıya kavuşmuştur. Enerji hem Rus ekonomisinin hem de Rus dış politikasının kaldıracı olarak kullanılmıştır. Bu kapsamda Yeltsin döneminde özelleştirilen Gazprom ve Rosneft gibi dev enerji şirketleri Putin döneminde tekrardan kamulaştırılmıştır. Enerji merkezli yeni Rus dış politikasında en önemli aktörlerinden biri Gazprom’dur. Putin'in 
iktidara gelmesiyle Gazprom, Kremlin' in dış politika aktörü olarak hareket etmeye başlamıştır. Putin iktidarının her alanda Rusya'nın gücünü kabul ettirme çabası Balkanlara da sıçramıştır. Konumu gereği Balkanlar, Rus enerjisi için hem bir transfer noktası hem de potansiyel bir pazar olmasından dolayı Rusya için oldukça kıymetli bir hale gelmiştir. Bu kapsamda Avrupa Birliği ile ilişkileri nispeten zayıf ve NATO üyesi olmayan Sırbistan, coğrafi konumu ve tarihsel bağlarından dolayı Rusya'nın ilgisini çekmiştir.

Mevküt Akçapa'nın kaleme aldığı ve Ocak 2020'de Dora Basım Yayın tarafından yayımlanan Rus Dış Politikasında Etkili Bir Aktör: Gazprom Putin Dönemi Rusya; Sırbistan İlişkilerinde Enerji Faktörü adlı çalışma, Putin döneminde Rusya'nın yeni dış politika eğilimleri kapsamında Rusya'nın Sırbistan ile kurduğu ilişkilerde ana aktör olan Gazprom şirketinin, Rus dış politikasının yapım süreçlerinde nasıl bir rol oynadığını açıklamayı amaçlamıştır. Bursa Teknik Üniversitesi, Uluslararası İlişkiler bölümünde görev alan Dr. Öğr. Üyesi Mevlüt Akçapa, Uluslararası İlişkiler, Türk Dış Politikası, Uluslararası Ekonomik Politik ve Rus Dış Enerji Politikası alanlarında çalışmalar yapmaktadır. Akçapa’nın kaleme aldığı bu eser üç ana bölümden oluşmaktadır. Eserinin birinci bölümünde "Uluslararası Ekonomik Politik" çerçevesindeki farklı paradigmalar ile uluslararası ilişsiler analizlerine yönelik ayırt edici yönleri açıklanmış, ikinci bölümünde enerji faktörünün Putin dönemi Rus dış politikası etkisini analiz etmiş ve üçüncü bölümde Rusya-Sırbistan ilişkilerini belirleyen önemli bir faktör olan enerjinin etkisi incelenmiştir.

Akçapa "Teorik Çerçeve" başlıklı birinci bölümde uluslararası ilişkilerdeki değişimlerin geleneksel teorilerle yeterince açıklanamaması sonucu ekonomik politik çatışmaların arttığını belirtmiş, devletlerin ve piyasaların karşılıklı etkileşimlerini teorik bir çerçevede incelemiştir. Akçapa, uluslararası ekonomi ve siyasetin büyük bir değişimden geçtiğini belirterek uluslararası ilişkiler uzmanlarının ekonomiyi yeterince önemsemediğini ve uluslararası ekonominin siyasetten uzak bir ortamda faaliyet gösterdiğini vurgulamaktadır. Bu durumun hatalı sonuçlar doğurduğunu söyleyen Akçapa, ekonomi ile siyaset arasındaki ilişkiyi ortaya koyarak bu iki disiplinin ortak bir paydada buluştuğu Ekonomik Politik çatısı altında değerlendirilmesi gerektiğini söylemiştir. Uluslararası Ekonomik Politik teorilerini farklı yaklaşımlarla değerlendiren Akçapa, üçlü bir sınıflandırma yöntemine giderek Liberalizm, Realizm ve Marksizm başlıkları altında Rus Dış politikasını anlamak için hangi Uluslararası Ekonomik Politik teorisinin en elverişli olduğunu ve diğer teorilerin neden tercih edilmediğini açıklamıştır. Bu bağlamda Akçapa, Putin dönemi Rus Dış politikasının realist ve pragmatist bakış açısı dikkate alınarak RusyaSırbistan ilişkilerinin enerji boyutunu değerlendirirken, realist yaklaşımların en uygun seçim olacağını düşünmüştür. Bu kapsamda Devlet Merkezli Realizm teorisini kullanan Akçapa, uluslararası organizasyonların ve devlet dışı oluşumların uluslararası ilişkilerde devletin karar alma mekanizmasının yerini aldığı düşüncesine karşılık yaşadığımız dünyanın hala devlet egemen bir dünya olduğunu savunmuştur.

Akçapa, "Putin Dönemi Rus Dış Politikasında Enerji Faktörü” başlıklı ikinci bölümde 
Putin iktidarının etkin bir dış politika için güçlü bir milli ekonomi hedefi ile yola çıktığını iddia etmiştir. Bu bağlamda Putin'in ulusal gücü kendi tekelinde toplayarak Rusya'da siyasi istikrarı sağladığı vurgulanmıştır. Dış politikada Rusya'nın enerjiyi en önemli aktör olarak kullandığını savununan Akçapa, Rusya'nın dünya siyasetinde etkinliğini arttırmak adına bu avantajını sonuna kadar kullandığını ve Rusya'nın küresel enerji güvenliğini için önemli bir aktör olduğunu belirtmiştir. Putin'in diş politikada enerji kozunu aktif bir biçimde kullanmak için Yeltsin döneminde oligarkların eline geçen enerji şirketlerini tekrar kamulaştırmıştır. Bunun ile Rus enerji sektörünün devlet kontrolüne geçmesinin sağlandığg belirtilmiştir. Devlet ve Gazprom arasındaki ilişkileri "Gazprom için iyi olan ne varsa, Rusya için de iyidir" düşüncesiyle açıklayan Akçapa, Putin'in en büyük projesi olan Gazprom'un uluslararası etkinliğinin ne kadar güçlü olursa Rus dış politikasının o kadar güçlü olacağ fikri üzerinde durmuştur. Bu bağlamda Rus dış politikasının kaldıracı olarak görülen Gazprom’un boru hatları diplomasisiyle etkinliğinin artırılmasıyla Rusya'nın etki alanının artacağı görüşünün Rus dış politikasında etkili olduğunu savunmuştur. Rusya'nın bütün doğalgaz ihracatının \%94'ünü Avrupa ülkelerine yaptığını ve AB'nin doğalgaz ihtiyacının \%25'ini Gazprom'dan tedarik ettiğini belirtmiştir. Akçapa, Gazprom'un dünya doğalgaz rezervlerinin \%17'sini elinde bulundurmasının sonucu olarak şirketin misyonunun Rusya'nın ve Putin'in dış politikasını takip etmek olduğunu belirterek Gazprom şirketinin doğalgazı nasıl bir dış politika silahı olarak kullandığ 1 veya kullanabileceği ve boru hatları diplomasisi gibi hususların Putin yönetimi tarafından nasıl analiz edildiğini ortaya koymuştur. Gazprom, Rosneft ve Lukoil gibi enerji şirketlerinin devlet kontörlüne geçmesiyle birlikte "Yeni Devlet Kapitalizmi" bağlamında bu şirketlerin yükselişinin görüldüğünü belirten Akçapa, Putin iktidarının bu şirketlerle birlikte küresel bir enerji imparatorluğu kurmayı, eski Sovyet ve doğu bloğu ülkelerini Rus gazına bağımlı hale getirmeyi hedeflediğini vurgulamıştır.

Akçapa, "Enerji Perspektifinden Rusya-Sırbistan İlişkilerinde Gazprom Faktörü” başlıklı üçüncü bölümde Gazprom örneği üzerinden Rusya-Sırbistan ilişkisini tartışmıştır. RusyaSırbistan ilişkilerinin tarihsel arka planı üzerinde durarak Sırbistan'ın Rusya için önemini açıklayan Akçapa, Rusya’nın Balkanlar üzerindeki çıkarları gereği kültürel ve dini bağları bir kaldıraç olarak kullandığını belirterek Rus dış politikasının tarihsel süreçte en önemli hedeflerinden bir olan "sıcak denizlere inme" isteği ve Slav halklarını birleştirme düşüncesinin devam ettiğini öne sürmüştür. 19. yüzyıldan itibaren Balkanların iç ve dış işlerine müdahale eden Rusya için Sırbistan'ın her zaman bu bölgede kıymetli olduğu belirtilmiştir. Bu sebeple Rusya'nın Sırbistan'ı çok sayıda siyasi ve bölgesel gelişmede desteklediğini belirten Akçapa, günümüzde ise tarihsel ve dini bağların yanı sıra ekonomik ilişkilerin iki ülke arasındaki etkileşimde öne çıkan unsur olduğunu öne sürmüştür. Putin döneminde Rusya-Sırbistan ilişkilerinin belirleyen faktörlerin Kosova Krizi, Karadağ'ın ve Kosova’nın bağımsızlığı, Sırbistan'ın AB üyelik süreci ve NATO ile ilişkileri gibi gelişmelerin şekillendirdiğini belirten Akçapa, AB'nin Sırbistan ile yakınlaşmasının Sırbistan'ı geleneksel Slav-Ortodoks iş birliğinden 
uzaklaştırma çabası olarak okumaktadır. Akçapa’ya göre batıya karşı Rusya, pozisyonunu netleştirmek için Sırbistan ile ilişkilerini “stratejik ortaklık” olarak tanımlamaktadır. İki ülke içinde bu tanım politik, ekonomik ve enerji alanlarındaki iş birliğini ifade etmektedir. Bu bağlamda Gazprom’un Sırbistan’a yapmış olduğu yatırımlar üzerinden iki ülke arasındaki ilişkiler analiz edilmiştir. Gazprom'un Sırp Naftna Industrija Srbije’nin (NIS) büyük bir bölümünü satın alması ile Rusya'nın bölgedeki nüfuzunu arttırdığını belirten Akçapa, böylelikle Rusya'nın, Hırvatistan, Macaristan, Bulgaristan ve Bosna Hersek'e gaz sağlayan üzerinde yeni bir pozisyon kazandığının altını çizmiştir. Öte yandan Gazprom'un Banatski Dvor yer altı gaz depolama tesisini hayat geçirmesi ile Rusya'nın, Sırbistan üzerindeki etkisini arttırdığını belirtmiştir. Akçapa'ya göre Putin, iptal edilen Güney Akım projesi bağlamında Balkanlara aktif bir oyuncu olarak geri dönmek istemekteydi.

Sonuç olarak bu eser, Rusya'nın Sırbistan ile olan ilişkilerini tarihsel süreç içerisinde ideolojik bağlamlara saplanmadan, uluslararası politik ekonomi ve ilişkiler perspektifinden anlaşılır ve objektif biçimde analiz etmiştir. Türkçe kaynakların yanı sıra birçok İngilizce kaynaktan da yararlanarak dünyadaki diğer akademisyenlerin konu hakkındaki fikirlerini de araştıran yazar, konu hakkında oldukça önemli bir çalışma ortaya koymuştur. Çalışma, uluslararası ilişkiler disiplininin ekonomi ile ne kadar ilişkili olduğunu ortaya koymuş ve Uluslararası Ekonomik Politiğin dış politika yapma aracı olarak ne kadar kilit bir rol üstlendiğini enerji üzerinden bizlere göstermiştir. Yazar, uluslararası ilişkiler ve ekonomi uzmanlarının birbirlerinin alanlarına müdahale edilmesini istememelerini eleştirerek iki alanda da çalışan akademisyenlerin iş birliğine giderek günümüzdeki ülkeler arası ilişkileri anlaması gerektiğini savunmuştur. Bu bağlamda kitapta bahsedilen Gazprom şirketi üzerinden Rusya'nın kendine nasıl nüfuz alanları oluşturduğu, ülkeler ile nasıl iş birliğine gittiği ve ekonomisini hangi dış ilişkilerle geliştirdiğini açıklamıştır. Yazar Rusya'nın enerji kaynaklarını bir aktör olarak kullandığını belirterek, dezavantajlı olduğu konularda bile enerji şirketlerinin iş birlikleri sayesinde masadaki pazarlıklardan karlı çıktığını belirtmiştir. Rusya ve enerji denklemi üzerinde önemli analizler yapan, Uluslararası Ekonomik Politiğin günümüz ilişkilerini anlamak için en faydalı araç olduğunu savunan bu eser, bu alanda daha sonra yapılacak olan çalışmalar için bir kılavuz niteliği taşımaktadır. 